\title{
Biodiesel production from unrefined palm oil on pilot plant scale
}

\author{
Jean Baptiste Nduwayezu, Theoneste Ishimwe, Ananie Niyibizi, Alexis Munyentwali" \\ Institute of Scientific and Technological Research (IRST), P.O. Box 227 Butare, Rwanda

\section{Email address:} \\ jbuwayezu@yahoo.co.uk (J. B. Nduwayezu), istheos@yahoo.fr (T. Ishimwe), niyibizan@yahoo.co.uk (A. Niyibizi), \\ alexmune@yahoo.fr (A. Munyentwali)
}

\section{To cite this article:}

Jean Baptiste Nduwayezu, Theoneste Ishimwe, Ananie Niyibizi, Alexis Munyentwali. Biodiesel Production from Unrefined Palm Oil on Pilot Plant Scale. International Journal of Sustainable and Green Energy. Vol. 4, No. 1, 2015, pp. 11-21.

doi: $10.11648 /$ j.ijrse.20150401.13

\begin{abstract}
As global warming and climate change issues are defying modern society sustainable development; biofuels, biodiesel included, are among promising solutions. Biodiesel is generally produced from renewable vegetable oils and animal fats via acid or base catalyzed transesterification. Depending on regional availability, biodiesel production feedstocks vary from vegetable oils such as rapeseed oil, soya oil, palm oil, and jatropha oil, to used cooking oil and animal fats, with each type of feedstock presenting its own process challenges rooting from its chemical composition. This paper reports about biodiesel production from crude palm oil on a pilot plant scale, subsequent to a laboratory scale investigation of biodiesel synthesis from various vegetable oil feedstocks. Prior to transesterification, pretreatment processes have been applied due to the fact that crude palm oil as a biodiesel feedstock possesses a high free fatty acid (FFA) content, water, solid impurities and waxes, all of which hinder an efficient transesterification if not dealt with accordingly. Those processes are mainly filtering, water evaporation, and FFA esterification which is done with $99.9 \%$ methanol and $96 \%$ sulfuric acid as a catalyst. In fact, the acid esterification process successfully handles the raw palm oil despite its high FFA content of $16.9 \%$, and biodiesel is produced from that feedstock with a yield of $90.4 \%$. A two steps transesterification is carried out using potassium methylate $32 \%$ in methanol as a catalyst and anhydrous methanol too. Laboratory analyses have also been used to monitor the process and assess the final product quality. Furthermore, biodiesel cold filtering and top layer intake tank systems of a filling station, both proved to be efficient at helping to obtain a refined product by getting rid of suspensions appearing in biodiesel at room temperature due to sterol glucosides and waxes.
\end{abstract}

Keywords: Biodiesel, Palm Oil, FFA, Acid Esterification, Transesterification, Environmental Friendly, Biodiesel Sediments

\section{Introduction}

Biodiesel has attracted considerable interest in recent years as an alternative, non-toxic, biodegradable and environmentally friendly fuel. It is defined as a mixture of monoalkyl esters of long chain fatty acids derived from renewable lipid sources; including vegetable oils, animal fat and algae oils, among others. These feedstocks are mainly composed of $85-98 \%$ wt triglycerides; three long fatty acid chains joined to a glycerol molecule [1].

Today, the most common biodiesel feedstocks are edible vegetable oils such as palm oil, soya bean oil, corn oil, and rapeseed oil. The main advantage of edible oils as feedstocks is that plantations and infrastructure are well established in most of oil producing countries, making these edible oils production expansion easier to meet the increasing demand.
Palm oil is by far a major component of global vegetable oil market. For instance palm oil is the world's most supplied of all edible oils; Malaysia Indonesia and Colombia being the world largest producers totalizing almost $83 \%$ of global production [2]. According to the US Department of Agriculture, during the $2013 / 2014$ period, palm oil dominated the world vegetable oil production (169.56MMT) with 59.06MMT, whereas soybean and rapeseed produced 44.66MT and 26.09MMT respectively [3]. In addition, palm oil per hectare production yield of 2,4041/acre/yr ranks among the highest comparatively to other biodiesel oil feedstocks [4]. As shown on Figure 1, in 2010 worldwide palm oil production was reported the most growing of the main biodiesel vegetable oils feedstocks for almost the 
previous six years.

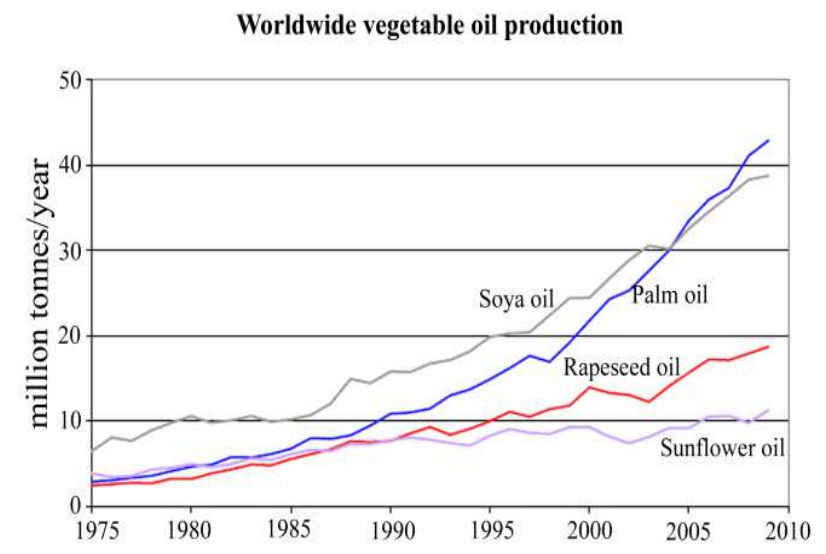

Figure 1. Annual growth of major edible oils production from 1975 to 2010 [4]

Depending on availability of feedstocks in different countries, biodiesel feedstocks preferences vary from country to country. For instance in the United States and Argentina soybean oil is the most used. European Union countries use rapeseed oil, whereas tropical countries such as Malaysia, Indonesia, Nigeria and Colombia prefer palm oil [2, 5].

What is more, the economic aspect of biodiesel production has shown to be the main hurdle. This is mainly due to high cost of feedstocks and a relatively low price of fossil fuels [6, 7].

As a result, evaluation of economic viability of biodiesel production is the most critical issue, due to high price of virgin and/or refined vegetable oils. The cost of feedstocks is revealed to account for $60-75 \%$ of the total cost of biodiesel fuel production. This is why feedstocks of low prices are essential to establish commercially viable biodiesel projects [8].

As it can be seen from the map on Figure 2, palm oil is actually the most abundant oil in the tropical regions where Rwanda is located.

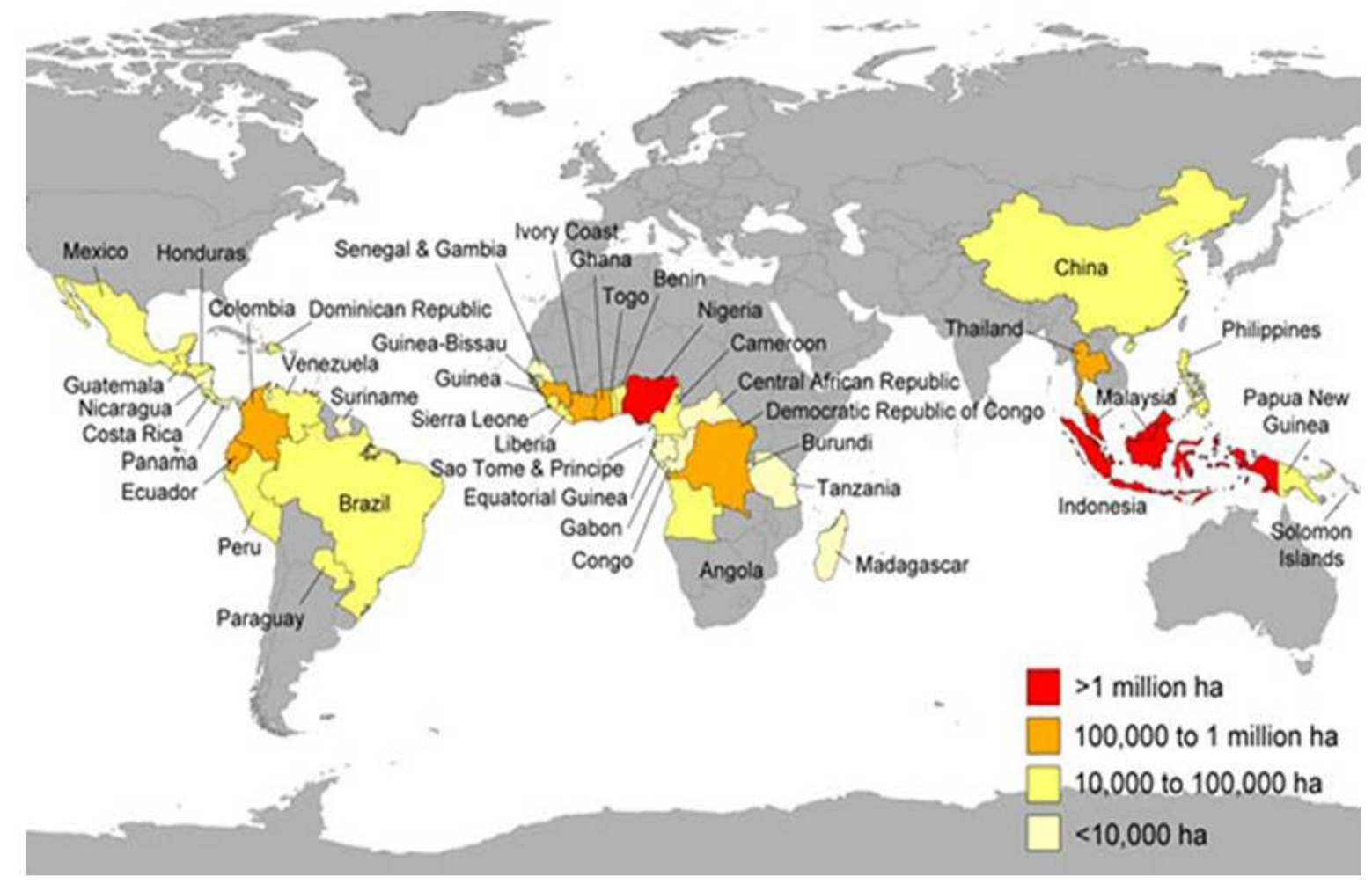

Figure 2. Palm oil cultivation in 43 countries worldwide [9]

In fact, as in many countries such as Malaysia for instance; the world second palm oil producer, the choice of biodiesel feedstock is driven by its affordability and availability. Therefore, being surrounded by palm oil producing countries, Rwanda is prone to use palm oil as biodiesel feedstock. Though the country targets $2^{\text {nd }}$ generation biodiesel mainly based on jatropha oil as a feedstock, palm oil has been used ever since the outset of biodiesel production in 2007. In spite of palm oil inestimable role in biodiesel production in Rwanda, refined palm oil is generally recommended for industrial biodiesel production, but this leads to the most controversial biodiesel disadvantage - that of being not cost effective when produced from refined feedstocks $[10,11]$. To ensure that biodiesel remains competitive over petroleum diesel, using crude palm oil may be the best option. However, conventional methods of using alkali catalyst to convert oils into biodiesel are not compatible with crude palm oil, given its inherent chemical composition. This is due to its high FFA content, high water content, insoluble impurities, etc [12, 13]. Crude palm oil is a low cost feedstock but associated with high content of FFA.

In fact, basic catalysts used to transesterify oils react with 
FFA to generate soaps and water, thus consuming the catalyst (Figure 3.a). The consumption of the catalyst leads to incomplete transesterification, which results in a mixture of diacylglycerol, monoacylglycerol, methyl esters, glycerol, water and methanol. This mixture is difficult to separate and therefore prevents formation of usable biodiesel. Furthermore, the water formed by saponification exacerbates hydrolysis of formed alkyl esters into FFA as shown in Figure 3.b [14].
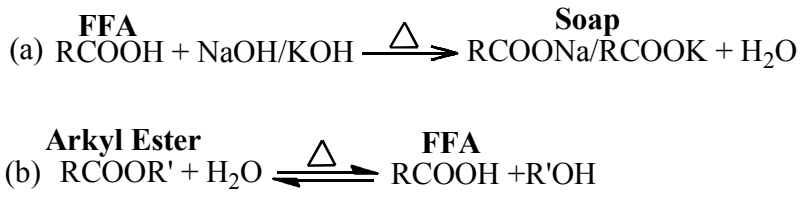

Figure 3. Parasitic reactions encountered in biodiesel production from oil high FFA and water contents [14, 15].

Traditional technologies mainly used for crude palm oil extraction in developing countries are responsible for high water content, which consequently increases FFA content with oil aging $[13,16]$. The common solution to overcome this issue is the use of refined oil. However, a system processing biodiesel from refined palm oil is technically successful, but not economically viable compared to using crude raw materials with pretreatment. In fact, refining will bring in FFA reduction, deodorization and bleaching, and require additional manpower and equipments, which will definitely increase the production cost [17]. Moreover, Dominik R. and Rainer J. argued that FFA which should have been converted into FAME is lost through refining, thus resulting in a decrease of the overall yield, especially if the feedstocks FFA content is high [12]. To this add the issue of cold flow properties of biodiesel which is a function of fatty acid composition. Since the type of feedstock plays an important role regarding the impurities and ways they must be removed, biodiesel from unrefined palm oil must be thoroughly purified and handled carefully. In fact, monoglycerides and sterol glucosides are at the origin of precipitations in biodiesel. Sterol glucosides are not soluble in biodiesel and crystalize slowly as the biodiesel cools down, and initial biodiesel seems to meet specification but after few days of storage filterability issue shows off. Sterol glucosides which are considered as dispersed fine solid particles as low as $35 \mathrm{ppm}$ may accelerate crystallization and coprecipitation of other compounds and creation of deposits in the biodiesel. Those deposits are at the origin of filter clogging at temperatures even above cloud point [18]. Furthermore, unrefined palm oil produced by traditional presses contains too much solid materials like sludges, fiber, palm seeds, leaves, and cakes which need to be removed before any pretreatment.

There are different technologies and processes applied in biodiesel production, each having its pros and cons:

- Base catalyzed transesterification process is the most preferred technology and most economical process since it has a conversion rate up to $98 \%$. It requires low temperatures and pressures, which leads to the use of usual equipments [19].
The drawback is that this technology needs raw oil of high purity, particularly with low water concentration and low FFA content. Otherwise saponification reaction sets in and competes with transesterification. The yield is proportional to the amount of catalyst but for economic purposes, the minimal amount of catalyst has to be used together with an optimal ratio of oil/alcohol [20].

- Acid catalysed process can produce biodiesel through both esterification and transesterification, but it is a very slow reaction requiring too much time up to one day for completion. It is also more corrosive than base-catalysed transesterification, requiring equipment of high cost $[19,21]$. Moreover, water generated when FFA react with alcohol to form esters limits the completion of acid-catalysed esterification [20]. To overcome problems associated with above mentioned processes, saponification in case of high FFA content for base catalysed process and slow reaction for acid catalysed, a two steps reaction is recommended; an acid esterification in case of raw material with high FFA content, followed by a transesterification [2].

- Enzymatic transesterification has gained interest recently, particularly because it produces less wastes, consumes less energy, and has got high efficiency and high selectivity. However, its wide spread application is hindered by the fact that involved enzymes are costly to produce, and reactions require delicacy in parameters control [19].

- Biodiesel production using solid catalysts is also interesting due to the catalysts reusability, the fact that it produces purer biodiesel and glycerol and has very high yields. This process is also less selective with regards to the raw material water and FFA contents. Nevertheless, it requires hash reaction conditions and the solids catalysts are deactivated over a number of cycles [14].

- Supercritical methanol method is another technique of making biodiesel but this time without using any catalyst. It offers high efficiency up to $100 \%$ and it is environmental friendly. It eliminates the steps of neutralisation, washing and drying. The feedstocks water and FFA contents have no effect on the reaction and both triglycerides and FFA are converted simultaneously into biodiesel. However the reaction tank should be oversized due to a high quantity of alcohol used with respect to oil(up to 42:1), high pressure over 80 atmospheres, and high temperature up to $350-400^{\circ} \mathrm{C}$. These conditions set the supercritical methanol process to harsh operating conditions and high costs [19].

There are other emerging biodiesel production technologies which do not use any catalyst. Among them there are:

Ultrasonic and microwaves enhanced transesterification show prominent advantages over base catalysed transesterification but these technologies need deep investigation before being applied to industrial production [19]

It's worth mentioning that biodiesel production from unrefined palm oil involves a set of chemical reactions which convert FFA and triglycerides into alkyl esters. These reactions are acid esterification and transesterification respectively. 


\subsection{Esterification}

Esterification is a reversible reaction in which FFA are converted to alkyl esters via acid catalysis usually $\mathrm{H}_{2} \mathrm{SO}_{4}$. Its general equation is as follows:

$$
\begin{aligned}
& \text { FFA } \\
& \mathrm{RCOOH}+\mathrm{R}^{\prime} \mathrm{OH} \underset{\text { Acid Cat. }}{\stackrel{\Delta}{\rightleftharpoons}} \stackrel{\text { Alkyl Ester }}{\text { RCOOR' }}+\mathrm{H}_{2} \mathrm{O}
\end{aligned}
$$

Figure 4. Acid catalysed esterification general equation [14].

\subsection{Transesterification}

The triacylglycerols (TAG) react with a light molecular mass alcohol in presence of a catalyst under heat through the following general reaction equation:

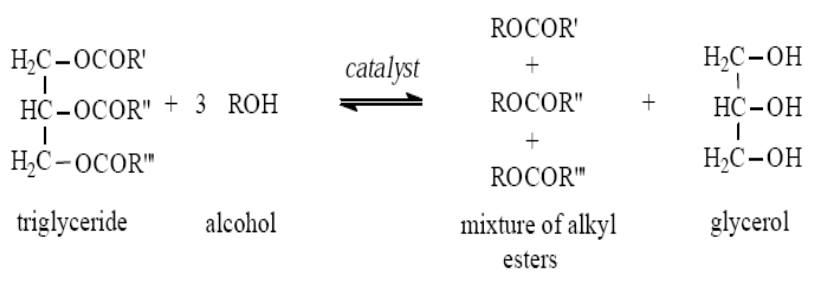

Figure 5. Transesterification general equation [14, 22]

Usually, methanol is the preferred alcohol because of its low cost. Ethanol is used in countries where its production cost is lower than that of methanol like in Brazil [14].

Transesterification happens in a three step reaction (Figure 6 ) in which three moles of FAME and 1 mole of glycerol are produced from every mole of TAG and 3 moles of alcohol $[14,17]$.

In this paper we report a successful biodiesel production from unrefined palm oil on a pilot plant scale by acid esterification of FFA, followed by a two steps alkali transesterification. For the sake of purification, this produced biodiesel is refined by a cleaning agent and then passed through a high speed separator followed by water evaporation under vacuum.

This study is a showcase of an economically viable process which optimizes production while ensuring quality standards, including biodiesel proper handling and storage up to delivery.

\section{Materials and Methods}

Rwanda is a landlocked country situated between $1^{\circ} 04^{\prime}$ and $2^{\circ} 51^{\prime}$ latitude south, and between $28^{\circ} 53^{\prime}$ and $30^{\circ} 53^{\prime}$ longitude east. It is a mountainous and lush country with a tropical weather and diverse ecosystems [23].

Research on Biodiesel production has been performed at IRST Biodiesel and Bioethanol Laboratory where a biodiesel processor is installed. It is designed to process $1,000 \mathrm{~kg}$ of raw oil per batch in $15 \mathrm{~h}$. The raw palm oil used is imported from neighboring countries, viz, Congo and Tanzania.

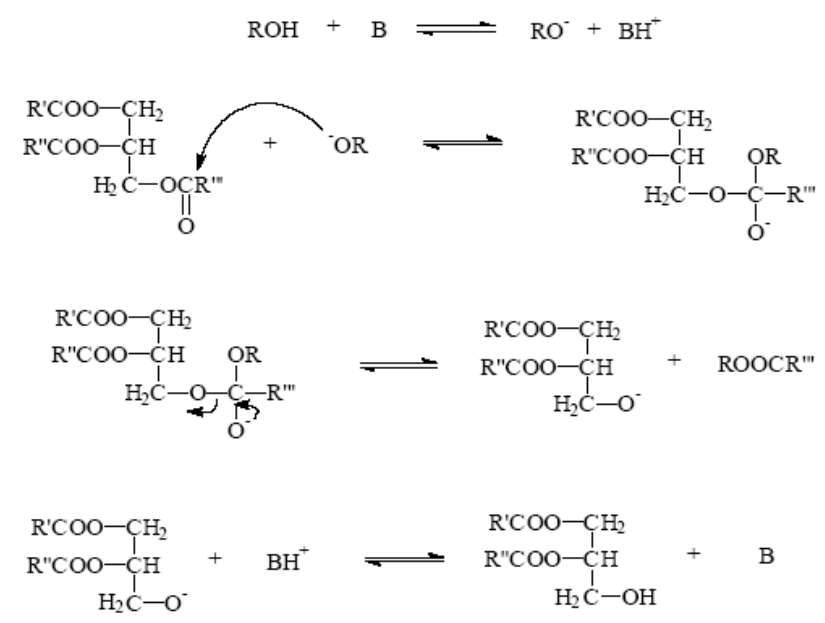

Figure 6. Transesterification reaction mechanism.

Chemicals used are mainly methanol $99.9 \%$, concentrated sulfuric acid $(96 \%)$, potassium methoxide $32 \%$ in methanol, manufactured by EVONIK, and ACA90 cleaning agent from AGERATEC. An installed SCADA program which monitors the process steps was designed by AGERATEC. Locally available materials and equipments have been used to solve issues raising from day to day production activities, namely a palm oil melting and impurities removal tank, a cold filtering system, and a biodiesel top layer intake storage tank. Regular analyses performed all along the process as well as on the finished biodiesel permit to comply with standards.

\subsection{Biodiesel Production from Unrefined Palm Oil by Acid Esterification Followed by a Two Steps Alkaline Transesterification}

\subsubsection{Laboratory Scale Production of Biodiesel}

Preliminary steps started in laboratory by determining appropriate triglycerides /catalyst/methanol proportions. The objective was to find optimum recipes which give higher triglicerides-methylesters conversion rates. Different types of oils such as refined and unrefined palm oil, soya oil, and jatropha oil were tested, and each type got its correct ratio determined for better efficiency. Incremental variations of $\mathrm{NaOH}$ amounts by $+/-0.05 \mathrm{~g}$ were investigated for $100 \mathrm{~g}$ oil samples.

During the laboratory oil tests for biodiesel, optimal proportions for the refined palm oil were found to be $0.35 \mathrm{~g}$ of $\mathrm{NaOH}, 100 \mathrm{ml}$ of oil, $20 \mathrm{ml}$ of $\mathrm{CH}_{3} \mathrm{OH}$. This gave two layers in the test tube, with biodiesel on top and glycerol at the bottom. Unrefined palm oil behaved differently. In the same conditions, using base catalyzed process to produce biodiesel from unrefined palm oil without changing catalyst-methanoloil ratio didn't give any positive results; the reaction formed a thick compound which didn't separate into distinctive layers.

\subsubsection{Oil Purification}

The crude palm oil comes packed in plastic bags from farmers. At the laboratory, the oil is stored in a heatinsulated PVC container $(F)$, as detailed on Figure 7. At room 
temperature this palm oil is semi-solid. A heating system has been designed to melt the oil for the processor loading convenience. The heating system consists of a welded aluminium container $(A)$ full of water, with heat insulation and located on top of $F$. Four electric heaters of $2,000 \mathrm{~W}$ each, set to heat the water up to $80^{\circ} \mathrm{C}$, are installed in the container. Inside the oil tank, coils of galvanized steel pipes are arranged at an angle of $120^{\circ}$ from one another, and joined to two collectors, one at the bottom of $F$ for water outlet, and another at its top for water inlet. The inlet pipe is connected to $A$ and the outlet pipe is connected to a 50 liters tank $(L)$ having a floater switch and a return pump connected to it.

\section{Mode of Operation}

Hot water from container $A$ flows by gravity through the coiled pipes in the oil tank. That hot water heats the oil by conduction and radiation. A valve mounted on $A$ is tuned to adjust the flow so that maximum heat is transferred to the oil. The water from three pipes collects in the collector at the bottom of $\mathrm{F}$ and flows into $L$. When $L$ is full, the floater switch activates the pump which then returns back the water to $A$. The cycle repeats continuously until a needed amount of oil is liquefied. Hot Water leaves $A$ at $80^{\circ} \mathrm{C}$ and reaches $F$ bottom at $40^{\circ} \mathrm{C}$. Liquefied palm oil in container $F$ is at about $35^{\circ} \mathrm{C}$.

Liquid oil is transferred to the processor via a pneumatic volumetric pump and a hose whose end floats in $F$ on the oil top layer. This pipe is equipped with an inlet nylon solid impurities filter. While oil is being liquefied, heavy solid impurities settle at bottom of $F$.

The processor is equipped with a heating system combining a heat pump and an electric boiler to generate heat and cold wherever they are needed along the process. In the preheating tank made of stainless steel with a whole bottom, oil is heated up to $65^{\circ} \mathrm{C}$. The entire floor of the tank is a heat exchanger that can give or get heat from the common hot water manifold. Then the hot oil passes through a $25 \mu$ polypropylene filter bag, sucked by a vacuum created in the pretreatment tank by a $500 \mathrm{~W}$ water sealed vacuum pump before proceeding to a vacuum water evaporation at $80^{\circ} \mathrm{C}$, which precedes the acid esterification. This vacuum water evaporation system reduces the interior pressure in the evaporation tank thus lowering the boiling point of the water and avoiding thermal decomposition of oil as well. In addition, the oil by passing through an atomizing nozzle on top of the tank, its evaporation surface increases, resulting in accelerating the evaporation. In addition, the water evaporation temperature is reached by means of a fusion heat exchanger in which hot water from the above mentioned heating system exchanges heat with the oil from the pretreatment tank.

\subsubsection{Acid Esterification Process}

Alkaline catalysts cannot directly catalyze the transesterification of oils containing high FFA. It has been reported that for alkaline transesterification to take place, FFA level in the oil should be below a desired level (ranging from less than $0.5 \%$ to less than 3\%) [23]. Acid catalyzed esterification intends to transform FFA present in the raw oil into methyl esters to prevent them from reacting with the base catalysts to form soaps.

In the acid esterification step, reactants proportions are of $11 \%$ of methanol and $0.8 \%$ of sulfuric acid $(96 \%)$, by raw oil weight. The reaction takes place at $80^{\circ} \mathrm{C}$ in a pressure proof tank under 2 bars, within a mixing time of 4 hours maximum.

This mixing is carried out by a static mixer coupled with a centrifugal pump. The static mixer has helical mixing element which directs the flow of the mixture radially towards the pipe wall and back to the center. The additional velocity reversal and flow division results from combining alternating right- and left -hand elements, increasing mixing efficiency of methanol and oil phases which are normally immiscible [10].

At the end of the mixing, sedimentation is required to let the glycerol settle from the rest of the mixture. After glycerol is drained out, three laboratory tests are performed to determine the conversion rate (methanol solubility- Jan Warnqvist test), acid number test and water content.

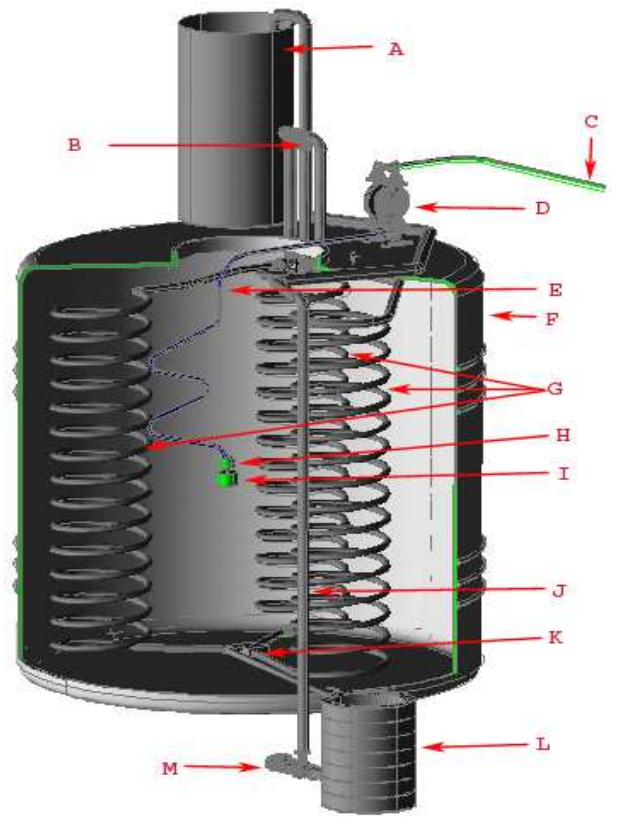

Figure 7. Raw oil hot filtering, sedimentation, storage and melting system designed in AUTOCAD (A: welded aluminium water tank, B:hot water outlet, $C$ : oil outlet pipe, D: oil pump to the biodiesel processor, E: oil inlet pipe, F: PVC container, G: hot water coils, H:floating ball, I: solid matter filter, J: return water pipe, $K$ : water collector box, L: water collection tank, $M:$ water return pump.

These tests results are fed to the processor's computer and from them it computes the remaining amount of methanol and potassium methylate to be used for the transesterification step.

\subsubsection{Alkaline Transesterification Process}

The triacylglycerols (TAG) react with a light molecular mass alcohol (methanol) in presence of a catalyst under heat as shown by the general reaction equation (Figure 5).

As soon as glycerol is drained out and routine tests are performed, a second intake of methanol is pumped to the batch. The whole content is then heated up to the reaction 
temperature $\left(55^{\circ} \mathrm{C}\right)$ and the required amount of potassium methylate is pumped in.

In order to shift the reaction equilibrium to the right, methanol is used in excess and transesterification is split into two steps, each step using half of the catalyst with a glycerin drain scheduled at the end of each step.

The excess methanol is recovered by static and dynamic evaporation under -0.9 bar vacuum and condensation. The static evaporation is done at rest in sedimentation phases, while dynamic is performed at the time biodiesel is being mechanically sprayed under vacuum. It's worth mentioning that before dynamic evaporation a deactivation step is carried out. This deactivation helps to prevent reversion of methyl esters and glycerol back to mono- and diglycerides in presence of residual methylate during dynamic evaporation of methanol. To this end, $6 \mathrm{wt} \%$ citric acid solution in methanol is added to deactivate traces of methylate present after transesterification. After its dynamic evaporation, methanol vapors are then sucked and condensed. Almost all the excess methanol is recovered, and it is reused after purification. This results in big savings on methanol costs.

\subsubsection{Biodiesel end Users Survey}

The produced biodiesel end users were required to submit a report detailing their experience using it in their cars. This was done by answering to a number of questions concerning any problem they might have encountered from filter premature change, engine performance, to joint usage and any fuel line issues.

\subsubsection{Biodiesel Purification}

After pumping the last glycerol phase out, the formed biodiesel may still contain traces of ions such as potassium, sodium, magnesium, calcium, glycerol residue, sediments and other solids. All these impurities must be removed, along with any water that might still be present after the reaction. After settling and glycerol draining, biodiesel is passed through a 9,512 rpm separator for glycerol separation. Then a cleaning agent, named ACA90, containing an inorganic chelating agent combines with impurities in the biodiesel to produce large, dense gum-like complexes which are then removed by a separator. Actually, within the separator the force of gravity is replaced by centrifugal forces, which can be thousands of times greater, and consequently achieving in few seconds the separation which could take many hours in a tank under the influence of gravity [24]. Finally, the washed biodiesel undergoes vacuum evaporation to remove excess water, and an antioxidation agent is added to improve the biodiesel oxidative stability. Then, the moisture free biodiesel is pumped to the biodiesel storage tank through a $0.8 \mu \mathrm{m}$ pore size cellulose cartridge filter to remove any residual solid particles.

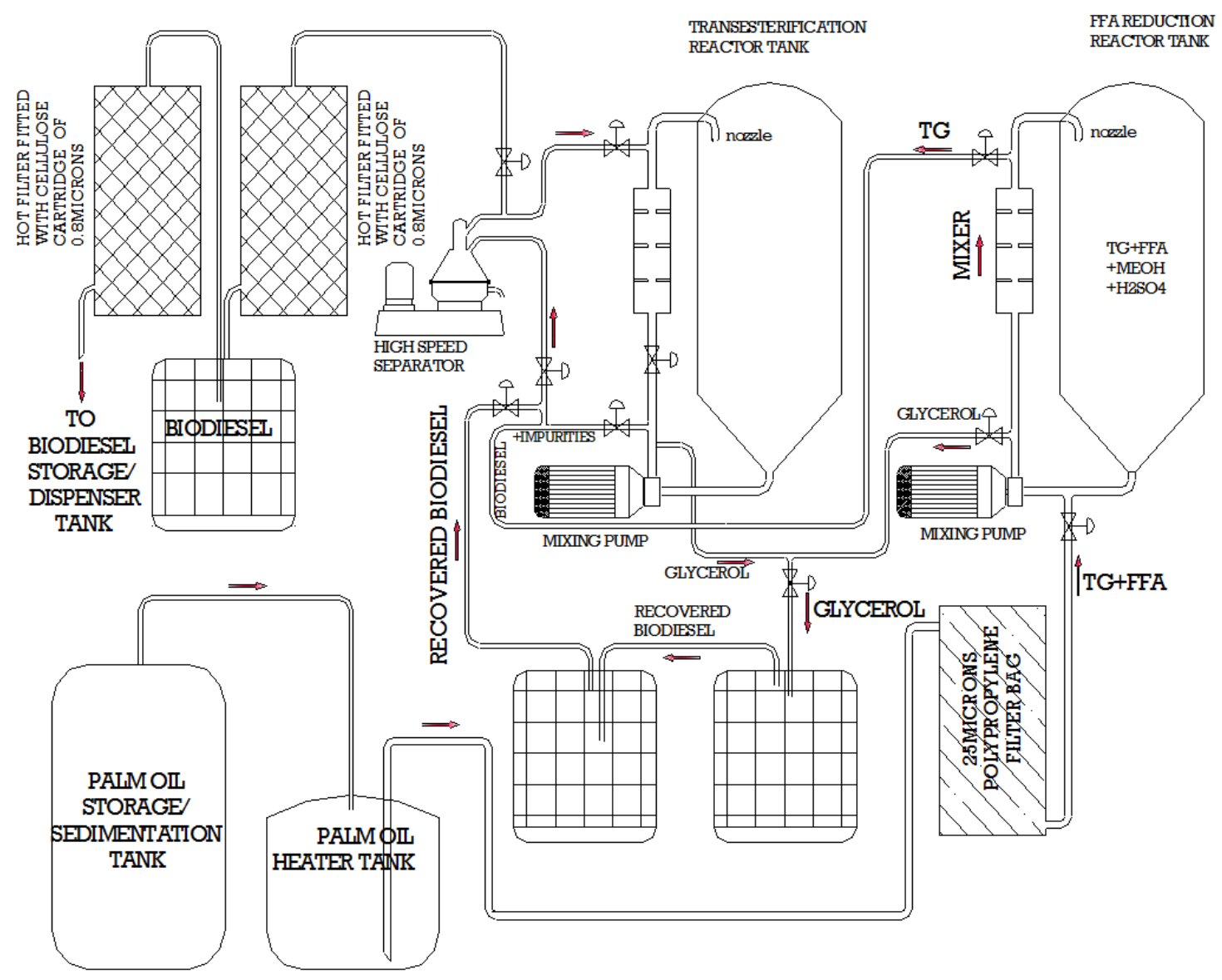

Figure 8. Flowsheet of the programmable biodiesel processor assembled by AGERATEC and used by IRST. 


\section{Results and Discussion}

\subsection{Efficacy of Reducing Solid Impurities in Raw Palm Oil}

One of the main roles of the palm oil purification unit is mainly to reduce solid impurities so that palm oil can be easily filtered. Crude palm oil is known to have a high amount of solid impurities as shown in Table 1. The purification unit allows the separation of melted oil from solids and this facilitates the oil flow through the pipes, and the purification equipments as well. The total amount of heavy solids contained in the raw palm oil was found to range from 5 to 10 percent of gross palm oil, as it is shown in Table 1.

Table 1. Some Physical-chemical properties of crude palm oil used (Laboratory analysis results by Rwanda Bureau of Standards)

\begin{tabular}{|c|c|c|c|}
\hline Analytes tested & Results & Method & Requirements \\
\hline $\begin{array}{l}\text { Volatile matter at } \\
105^{\circ}, \mathrm{m} / \mathrm{m}, \max \end{array}$ & 0.75 & AOAC926.12 & $0.2 \%$ \\
\hline Acid value, $\mathrm{mgKOH} / \mathrm{g}$ Oil & 31.70 & AOAC940.28 & 10 \\
\hline $\begin{array}{l}\text { Peroxide value milli- } \\
\text { equivalent of active } \mathrm{O}_{2} / \mathrm{kg} \\
\text { oil }\end{array}$ & 1.90 & AOAC965.33 & Up to 15 \\
\hline Saponification value & 227.00 & AOAC 920.160 & NA \\
\hline $\begin{array}{l}\text { Insoluble impurities, } \% \\
\mathrm{~m} / \mathrm{m} \text {, max. }\end{array}$ & 6.6 & ISO 663 & $0.05 \%$ \\
\hline
\end{tabular}

\subsection{Process Analysis}

\subsubsection{Evaluation of Free Fatty Acid Reduction by Acid Number Test}

Feedstocks high in free fatty acids are not easily converted by homogeneous base transesterification, because of the concurrent soap formation reaction of the free fatty acids with the catalyst. The excessive amount of soap formed significantly interferes with the washing process by forming emulsions, thus leading to substantial yield losses $[25,26]$.

FFA are released naturally in crude palm oil and can be increased by the action of enzymes in the palm fruit and by microbial lipases. During storage, FFA are produced by hydrolysis of triglycerides. Approximately $98 \%$ of crude palm oil is made up of fatty acids as shown in Table 2.

Table 2. Palm oil fatty acid composition [27-29].

\begin{tabular}{llll}
\hline Fatty acid & Formula & Structure (x, y) & $\begin{array}{l}\text { Palm Oil (\% } \\
\text { by weight) }\end{array}$ \\
\hline Palmitic acid & $\mathrm{C}_{16} \mathrm{H}_{32} \mathrm{O}_{2}$ & $\mathrm{C} 16: 0$ & 32 to 47 \\
Oleic acid & $\mathrm{C}_{18} \mathrm{H}_{34} \mathrm{O}_{2}$ & $\mathrm{C} 18: 1$ & 39.1 to 52 \\
Linoleic acid & $\mathrm{C}_{18} \mathrm{H}_{32} \mathrm{O}_{2}$ & $\mathrm{C} 18: 2$ & 2 to 11 \\
Stearic acid & $\mathrm{C}_{18} \mathrm{H}_{36} \mathrm{O}_{2}$ & $\mathrm{C} 18: 0$ & 1 to 6 \\
Myristic acid & $\mathrm{C}_{14} \mathrm{H}_{28} \mathrm{O}_{2}$ & $\mathrm{C} 14: 0$ & 0.8 to 6.0 \\
Lauric acid & $\mathrm{C}_{12} \mathrm{H}_{24} \mathrm{O}_{2}$ & $\mathrm{C} 12: 0$ & 0.3 to 1.0 \\
\hline
\end{tabular}

For the palm oil feedstock used in this research, whose FFA content is particularly high as confirmed by its acid number (Table 1), typical homogenous base catalyst (methoxide) cannot be effective due to the unwanted side reaction as shown in Figure 3.a.

Acid pretreatment (acid esterification) is used to lower its
FFA content prior to transesterification. In this research, since the esterification step is catalyzed by a strong acid; $\mathrm{H}_{2} \mathrm{SO} 4$ $96 \%$ whose main part is drained out together with glycerol, some residual acidity stays in the oil/biodiesel mixture. Thus, the total acid number includes the residual acidity from both of the catalyst and FFA contribution.

The acid number test is used to determine the acidity (FFA and residual acid catalyst concentration) of the mixture to be neutralized by the potassium methylate before transesterification. Therefore, the base catalyst required for transesterification will be increased by the amount of the base to neutralize the above mentioned acidity. The test is done by titration of a sample taken just after the first glycerol drain, with $0.1 \mathrm{M}$ potassium hydroxide aqueous solution and phenolphthalein as indicator.

The acid number is reported as $\mathrm{mg} \mathrm{KOH} / \mathrm{g}$ according to the following formula:

$$
A=\frac{56.1 x V x c}{m}
$$

$V$ is the volume (ml) of the $\mathrm{KOH}$ solution used for the titration of the sample $C$ is the concentration in moles per litre (M) of the $\mathrm{KOH}$ solution $m$ is the mass of the sample in grams $(\mathrm{g})$ 56.1 is the molar mass of $\mathrm{KOH}$

Note that the acid number (A) can be converted into FFA value. This FFA value is reported as a percentage of oleic acid according to the following formula : $F F A=\frac{A}{1.875}[30]$.

Table 1 and Table 2 show that the acid esterification process reduces FFA content from $16.91 \%$ for crude palm oil to $2.44 \%$; which is a reported average of 71 batches. The difference being the amount of FFA converted into FAME (biodiesel) through the esterification reaction. It's worth mentioning that $2.44 \%$ FFA is lower than $3 \mathrm{wt} . \%$, the value above which base catalysed transesterification reaction will be significantly hindered due to the unwanted reaction in which the catalyst reacts with FFA to form soap and methanol, thus irreversibly quenching the catalyst and resulting in an undesirable mixture of FFA, unreacted TAG, soap, diacylglycerol (DAG), monoacylglycerol (MAG), biodiesel, glycerol, water, and/or methanol [31].

The average acid number from a series of tests for 71 batches is 4.57, and as shown in Table 1 and Figure 10, the water content of samples taken after the first glycerol drain, a subsequent step to the acid esterification, increases with the acid number also measured after this step. This suggests that the higher the FFA content, the higher the water content at this stage. From Figure 9, the water content before transesterification start is proportional to the water content of palm oil before acid esterification. Therefore, the higher the water content before acid esterification, the higher the acid value and the higher the amount of potassium methylate required to neutralize this acid. It is very important to evaporate water from raw oil in order to optimize biodiesel production. 


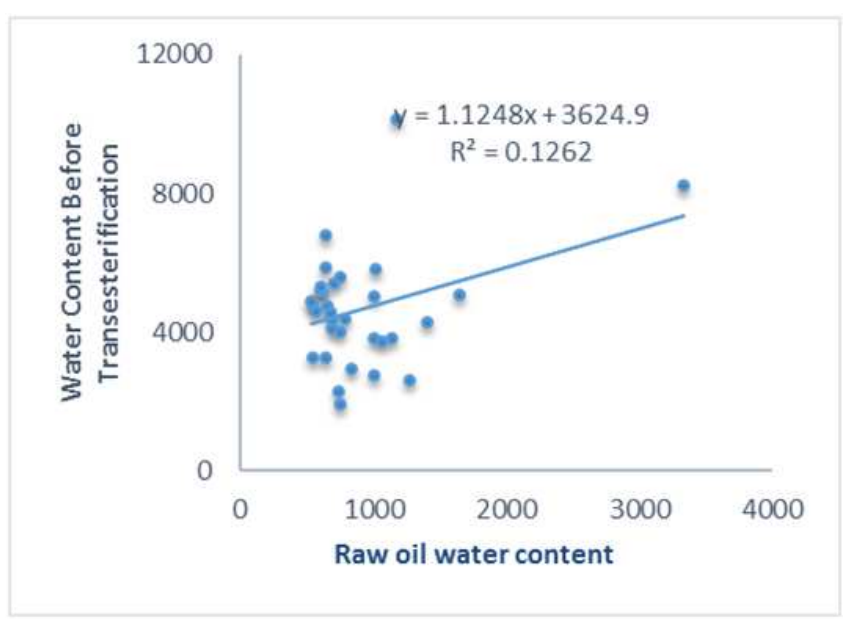

Figure 9. Relationship between water content of raw oil before and after acid esterification.

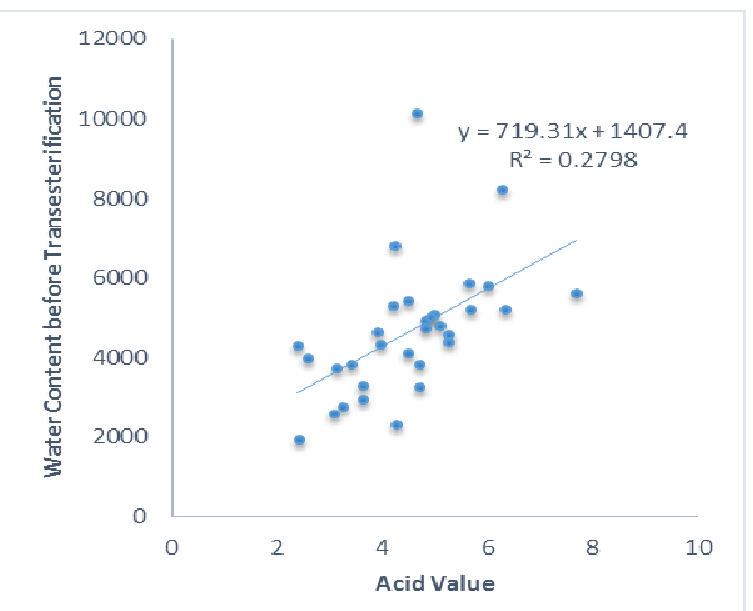

Figure 10. Relationship between water content before transesterification and acid number.

\subsubsection{Determination of Oil Conversion Rate by Methanol Solubility Test (Jan Warnqvist test)}

Methanol solubility test reveals the rate of oil conversion just after esterification, and the transesterification level of the produced biodiesel. The test assumes that the methyl esters are fully soluble in anhydrous methanol and that the oil is not. The test is performed by mixing a sample of oil \& biodiesel mixture with anhydrous methanol in a separatory funnel. After mixing, the two layers are allowed to separate, the bottom layer (oil) is collected, dried and then weighed The methanol solubility expressed as a percentile is then calculated as follows: $\left(1-\frac{m_{2}}{m_{1}}\right) x 100$, where $\mathrm{m}_{1}$ represent the sample weight $(\mathrm{g})$ and $\mathrm{m}_{2}$ the weight $(\mathrm{g})$ of the oil phase [32].

With the use of this test, data collected from August 2008 to December 2011 for methanol solubility tests showed that the acid esterification average conversion rate is of $57 \%$. This means that the acid catalyzed transesterification also happened simultaneously with the acid esterification, since the average raw oil FFA content is of $16.9 \%$ only. This concurs with the fact that acid transesterification is also possible even though it occurs very slowly. For samples taken after transesterification, the rate is $99.8 \%$, meaning a nearly complete conversion of oil into methyl esters (biodiesel).

\subsubsection{Water Content Measurements [33]}

The water content either in oil or in biodiesel, is determined by Karl Fischer coulometric titration as described by the standard EN ISO 12937.

On one hand, from observing the raw oil remaining water content as shown on Figure 11, it's obvious that this quality of oil contains so much water that even after three to four hours of water evaporation, its average water content stays above 1,000ppm; the recommended threshold before chemicals input. On the other hand, water content increases at the end of the esterification step (Figure 4\&11), with an average of $4,646 \mathrm{ppm}$, and this is due to the water produced by the FFA esterification reaction.

Water content of the produced biodiesel is also measured for each batch. For 71 batches, the average water content was calculated to be of $395 \mathrm{ppm}$, a value that falls far under the EN14214 standard (500ppm). This means that the process is very efficient on this parameter in spite of the high water content of the starting raw oil.

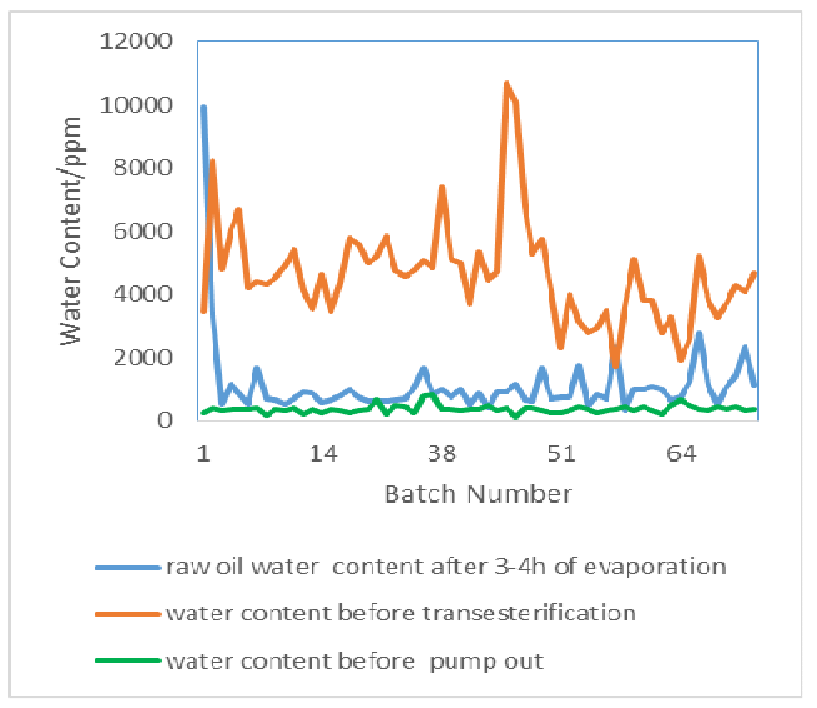

Figure 11. Water content trends along the process

\subsubsection{Palm Oil Biodiesel Cold Flow Behavior}

In some cases, biodiesel 100\% (B100) used into diesel engines may clog filters. Table 3 summarizes results of the biodiesel end users survey.

Table 3. End users survey results.

\begin{tabular}{ll}
\hline Issue & Report \\
\hline Any problem while & $6 \%$ changed filters unexpectedly and 94\% didn't \\
using biodiesel & face any problem \\
& $100 \%$ didn't experience any joint wear nor \\
Joint usage & $100 \%$ didn't notice any wearing nor change \\
Fuel lines & $9.6 \%$ changed filters, 90.4\%didn't \\
Fuel filters changing & $92.8 \%$ reported filter didn' t show any problem, \\
Filter clogging & $7.2 \%$ reported clogged filters \\
\hline
\end{tabular}


Note that when biodiesel cools down, solid deposits are formed. These precipitates may be sterol glucosides [18], waxes, mono and diglycerides, which are liquid at $80^{\circ} \mathrm{C}$ and not detectable by methanol solubility test, but unfortunately solidify and become visible at room temperature.

\subsubsection{Solutions to Biodiesel Sediments}

In order to get rid of those occurred impurities, a cold filtering and a top layer intake biodiesel tank systems were designed.

\subsubsection{Cold Filtering System}

This system comprises a tank, a $0.8 \mu$ cellulose filter, a tightening nut, a cover disk with bolts, an inlet, an outlet and a pump.

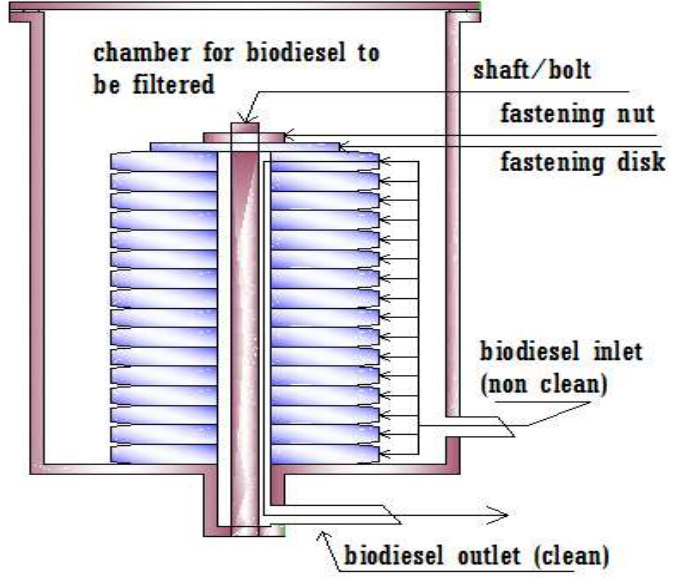

Figure 12. Biodiesel filter

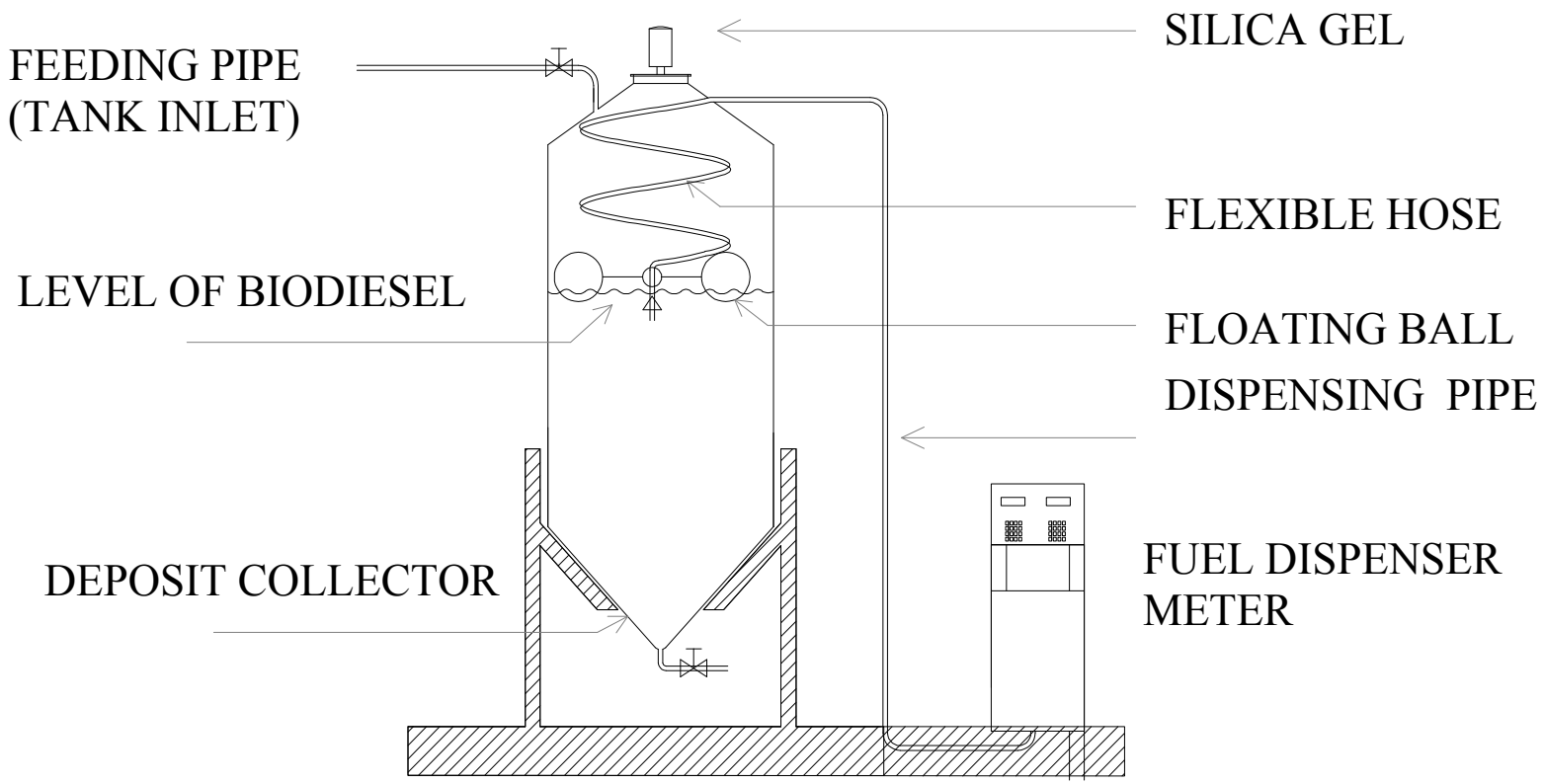

Figure 13. Biodiesel settling tank system

Mode of operation: The pump pushes biodiesel with suspensions through the room between the filter and the tank wall. The only way by which the biodiesel has to get out is through the cellulose filter and via the outlet, leaving behind suspended impurities. Figure 12 depicts the cold filtering system.

The pump stroke is kept low to minimize the pressure that would force precipitates through the filter. This system is so efficient that it removes almost all impurities (99\%) and cars using biodiesel filtered this way never faced any problem of filter clogging at all.

\subsubsection{Biodiesel Filling Station Tank System}

A new biodiesel storage and delivery tank (Figure 13) was specifically designed to let any remaining sediments settle at the bottom, and biodiesel to be taken from the top layer. The tank has a conic bottom with a $45^{\circ}$ angle slope. The biodiesel intake pipe is attached to a flexible hose, itself always kept at the biodiesel top layer by floating spheres which also permit the intake pipe to follow biodiesel level.
A minimum level of biodiesel is kept in the tank $(5 \%$ of tank capacity) to prevent the filling pump from sucking presumed dirty biodiesel at the bottom. The arrangement is also equipped with a non-return valve which keeps the filling pump inlet pipe always full, to prevent the pump from sucking air and allow the pump to start sucking since it is of centrifuge type.

Furthermore, the filling pump itself has filters which may retain unexpected impurities.

Additionally, since biodiesel is hygroscopic, a silica gel cartridge is installed on the tank top cover, to retain air moisture when the filling tank is sucking air.

\section{Conclusions}

The production of biodiesel from low-cost raw materials which generally contain high amounts of free fatty acids (FFAs) is a fascinating alternative that would make their production costs more competitive than petroleum-derived 
fuel. A good quality biodiesel can be produced from crude palm oil by base catalysed transesterification, after a simple and cheap oil purification accompanied by acid esterification pretreatment to reduce FFA content. This technology was applied on a pilot plant scale with an automated biodiesel processor machine in Rwanda and showed to be promising. In this plant, biodiesel is produced with a yield of $90.4 \%$ and laboratory analyses have proved its quality to be acceptable on common biodiesel parameters. This was also confirmed by end users survey which showed their high satisfaction in various dimensions such as low carbon emissions, engine performance, and local cold weather operability. In all, the findings are industrially applicable, economically viable and repeatable. For a landlocked country like Rwanda, which doesn't possess any petroleum resources, biodiesel production from low cost raw materials (crude palm oil) even abundant in the region, may constitute a promising alternative to its energy security.

\section{References}

[1] Adriana G., Marious R., Monica T., Csaba P. and Florin D. I.(2012). Biodiesel production using enzymatic transesterification e Current state and perspectives. Renewable Energy . 39: 10-16.

[2] Rincón L.E., Jaramilo J.J., Cardona C.A.(2014). Comparison of feedstocks and technologies for biodiesel production: An environmental and techno-economic evaluation. Renewable Energy. 69: p. 479-487.

[3] USDA. OIlseeds: World Market and Trade. (2014).P: 7.

[4] Frank R.C., Luc. P., and Arnaldo W. A global overview of vegetable oils, with reference to biodiesel. (2009). IEA, London. P: 9,19.

[5] FOE.(2006).The use of palm oil for biofuel and as biomass for energy. Available from: www.foe.co.uk/sites/default/files/.../palm_oil_biofuel_positio n.pdf. Accessed on 12/8/2014.

[6] Atadashi I.M., Aroua M.K., Abdul Aziz A.R., Sulaiman N.M.N. (2012). Production of biodiesel using high free fatty acid feedstocks. Renewable and Sustainable Energy Reviews. 16: 3275-3285.

[7] Antolin G., Tinaut V.F., Briceno Y., Castano V., Perez C., and Ramırez A.I.(2002). Optimisation of biodiesel production by sunflower oil transesterification. Bioresour Technol. 83:111114.

[8] Huang G., Chen F., Wei D., Zhang X.W., and Chen G.(2010). Biodiesel production by microalgal biotechnology. Appl Energy . 87: 38-46).

[9] ACET. (2013). The Oil Palm Value Capture Opportunity in Africa. Accra, Ghana. P: 11.

[10] Gerhard K., Jon V.G., and Jurgen K. The Biodiesel Handbook, 2005. AOCS Press. Illinois-USA. pp.9,15,55 and 236.

[11] Szulczyk K.R., The economics of malaysian palm oil industry and its biodiesel potential.(2013). Social Science Research network.
[12] Rutz D., Rainer J., Biofuels Technology Handbook.( 2007). WIP renewable energies: Munich-Germany. p. 73,78,87.

[13] Poku K., Small Scale Palm Oil Processing in Africa.( 2002). FAO.p: 9,11.

[14] Caye M. D., Nghiem P.N., Terry H.W., Biofuel Engineering Process Technology $1^{\text {st }}$ ed.( 2008). McGraw-Hill Professional, New York. p. 197-200,202-204.

[15] Jawad N., Syed K., Farrukh N.(2008). Palm Biodiesel an Alternative Green Renewable Energy for the Energy Demands of the Future. ICCBT. F(07): 79-94.

[16] Nyanjou R.N.(2008). Modernisation and Innovation of Palm Oil Extraction Process: The Palm Nut, Its By-products and Its Properties, in IAALD -AFITA -WCCA World Conference On Agricultural Information And IT . Tokyo.

[17] Moser B.R., Biodiesel production, properties, and feedstocks.(2009). In Vitro Cell .Dev.Bio.-Plant. 45:229-266.

[18] Inmok L, Lisa M.P., George B.P., Erica P., and Troy H.(2007). The Role of Sterol Glucosides on Filter Plugging. Biodiesel Magazine. Available on http://www.biodieselmagazine.com/articles/1566/the-role-ofsterol-glucosides-on-filter-plugging/. Accessed on 15/09/2014.

[19] Refaat A.A.(2009). Different techniques for the production of biodiesel from waste vegetable oil. International Journal of environmental science and technology.7 (1):183- 213 .

[20] Alemayehu G., Abile T. (2014). Production of biodiesel from waste cooking oil and factors affecting its formation: A review. International Journal of Renewable and Sustainable Energy. 3(5): 92-98.

[21] Khalid Khalizani, Khalisanni Khalid.(2011). Transesterification of Palm Oil for the Production of Biodiesel. American Journal of Applied Sciences. 8 (8): 804809.

[22] Roger A., Isabel A., Ulf H., Green Chemistry and catalysis, 2006.wiley. p373.

[23] Sharma Y.C., Sing.B.(2009). Development of biodiesel: current scenario. Renewable and Sustainable Energy Reviews. 13:1646:51.

[24] Falconer A. (2003).Gravity separation: old technique/ new methods. Physical separation in science and engineering. 12(1): 31-48.

[25] Godlisten G.K., Abraham.K.T., Hassan M.R., Godwill D.M., Jibrail K.,and Keat T.(2013). Pre-Treatment of High Free Fatty Acids Oils by Chemical Re-Esterification for Biodiesel Production: A Review. Advances in Chemical Engineering and Science.3: 242-247.

[26] Freedman B., Pryde E.H., and Mounts T.L. (1984).Variables Affecting the Yields of Fatty Esters from Transesterified Vegetable Oils. Journal of the American Oil Chemists Society. 61: 1638-1643.

[27] Dennis Y.C.L., Xuan W., Leung M.K.H.(2010). A review on biodiesel production using catalyzed transesterification. Applied Energy. 87 :1083-1095.

[28] Kansedo J, Lee K.T, Bhatia S.C.O. (2009). Oil as a promising non-edible feedstock for biodiesel production. Fuel. 88:114850 . 
[29] Srivastava A., Ram. P.(200). Triglycerides-Based Diesel Fuels. Renewable and Sustainable Energy Reviews.4:111-33.

[30] Europian Committee for Standardization.(2003). Fat and oil dereivatives-Fatty Acid Methyl Esters (FAME)-Determination of acid Value, in EN14104: 2003E. Swedish Standards Institute. P: 3-7.

[31] Lotero E, Liu Y., Lopez D.E.,Suwannakarn K., Bruce D.A, Goodwin J.G. Jr.(2005). Synthesis of biodiesel via acid catalysis. Ind.Eng. Chem. Res. 44:5353-5363.
[32] Young R.(2008). Field Test Equipments Enhances Quality Assuarance. Biodiesel Magazine .p :3.

[33] ISO. European Standards (2000). Petrolium products Determination of water - Coulometric Karl Fischer titration method(ISO 129:2000).CEN. 